Urban and Maritime Transport XXVII 131

\title{
IMPACT OF COVID-19 ON SHARED MOBILITY: A STUDY OF BANGALORE, INDIA
}

\author{
GARGI GHOSH \\ Sky Group, India
}

\begin{abstract}
Shared mobility has been documented as one of the most common urban transport services and one of the fastest growing service markets of recent times. In India, the shared mobility market was poised to grow at a CAGR of $13.7 \%$ in the period 2019-2025 with a fleet size of two million units in 2019 . However, the global pandemic has had an extraordinary impact on the shared mobility space. Bangalore is one of the most prominent metropolises of Asia. The city is India's Silicon Valley, and attracts people from all across the country. Planning for mobility is an important aspect of a growing metropolis, and Bangalore appears to be an excellent area for exploratory research. This study presents the challenges and opportunities presented by the COVID-19 on shared mobility in Bangalore. The World Health Organization (WHO) has recognised the novel coronavirus thereafter called COVID-19, as the greatest pandemic in a century. The global pandemic has impacted human activity in unprecedented ways. Working situations have changed globally with a significant segment of workers moving to remote working situations. Schools, colleges and other educations institutions have fast adapted to the online mode. Leisure trips have taken a back seat. In light of these significant changes in lifestyle several research works in the field of urban transportation highlight the changing travel pattern and preferences of the urban users. The study presents the user perceptions towards shared mobility modes and changed travel patterns in Bangalore in the wake of COVID-19 through a user survey. The study includes a documentation of the government issued COVID related standard operating procedures (SOPs), altered travel patterns, perceived and real barriers to travel and the attitude of users to shared mobility.

Keywords: COVID-19, user perception, shared mobility, bike share, rideshare, car share, ride splitting, ride sourcing, Bangalore.
\end{abstract}

\section{INTRODUCTION}

Shared mobility has been documented as one of the most common urban transport services and one of the fastest growing service markets of recent times. In India, the shared mobility market was poised to grow at a CAGR of $13.7 \%$ over the $2019-2025$ period [1]. Studies in conducted pre COVID-19 outbreak have shown that shared mobility services form a significant mobility mode in India used by user groups of cross cutting economic, social and age groups [2]. It has also been established that shared mobility services in the form of bike share, ride-share, ride-hailing and ride-splitting form a significant part of commuting and leisure trips.

The SARS-CoV-2, commonly known as COVID-19 emerged as a global pandemic in the year 2020. The virus affected 10.9 million people in India with 0.15 million deaths [3]. In Bangalore 0.4 million cases were registered until February 2021 with a mortality rate of $1.1 \%$ [4]. COVID cases started emerging in India in late February 2020. In response to the rising cases the Government of India ordered a nation-wide lockdown on March 24th 2020 for an initial period of 21 days which was later extended till May 31st 2020. The lifting of the curfew and measures termed as 'Unlock 1.0' came with strict protocols for travel, gathering and business hours. The peak active cases in India appeared in September 2020 [5] where after there was a steady decline in active cases, new cases as well as deaths related to COVID-19.

There was a startling shift in economic activities and business processes in the wake of the pandemic. Businesses, education and major lifestyle-based ac moved to an online mode. 
Public transportation (including metro rail, intercity railway, bus service) were either shut or reduced service frequency to reduce the transmission rates and shopping moved to a largely online/home delivery platform.

These changing dynamics have added new dimensions to mode choice and travel patterns. There is significant ongoing and published research on the impact of COVID-19 on mobility globally, however research data and results on COVID-19 impact on shared mobility is limited. There have been some research findings in the Indian context as well on the altered mobility patterns post COVID. However, there is no data on COVID impacted scenario focusing on shared mobility in Bangalore. Recognition of these changes is important to understand the long-term impact of COVID-19 on shared mobility service market. This paper intends to bridge the gap by presenting survey results focusing around impact of COVID-19 outbreak user perception towards shared mobility and changed travel patterns in Bangalore city.

\section{LITERATURE REVIEW}

Shared mobility can be defined in terms of the vehicle-type, usage types, business model or technology. Shared mobility is an "umbrella" term that refers a broad array of innovative transportation modes with different use cases, business models, and travel behaviour impacts [6]. The market for personal mobility is being changed quickly due to structural modifications [7] of the social and cultural trends, as well as technological advances such as smartphones, Internet of Things (IoT), Big Data, Cloud Computing, information processing, and widespread data connectivity. Shared mobility is an innovative transportation concept, which can be considered as a set of disruptive mobility services [8] enabling urban trip planning, booking, real-time information, and fare payment into a single-user interface.

The literature review captures the pre-COVID trends of shared mobility market and the impact of COVID-19 related guidelines on shared mobility in the global context. Availability of research data on mobility and shared mobility in the Indian context has also been presented along with research techniques used for studying the impact of COVID-19 on transportation and mobility services.

\subsection{Impact of COVID-19 on mobility}

The COVID-19 brought about a fundamental change in the business processes in the economy. Spurred by the lockdown regulations major economic sectors like banking, financial sector, IT and ITES services, retail, education, healthcare have moved to a remote working mode. The uncertainty related the changing landscape of guidelines, procedures and unpredictability of the disease itself has forced businesses and decisions makers to a faster adoption of digital technology in business processes and a transformation of the business models [9]. The impact of the COVID-19 pandemic hence is expected to have far reaching effects on the economy that would last beyond the predicable lifecycle of the pandemic. Behavioural response to the COVID-19 is also expected to bring about some natural changes in travel behaviour. Study of these changes in travel pattern and mode choice is important in transportation planning.

Studies on preliminary changes mobility pattern due to COVID-19 has been conducted in various countries. Road traffic during the pandemic fell to 1955 levels in the UK [10] and many countries saw spectacular drop in public transport ridership. It has been found that social distancing is likely to lead to a reduced travel demand and reduced usage of public transportation [11]. Survey conducted in Australia indicated that there was a fall in the total trips and an increase in trips using private modes. The same study reflected the user 
perception of private modes being safer than public modes like buses and trains [12]. Similar surveys in UK, Budapest, Chicago exhibited a pattern of public transportation modes being perceived unsafe due to potential risk of exposure to coronavirus and private modes such as bikes, cars being perceived as safe [13], [14].

There has been some research in the Indian scenario as well focusing on mobility in the post COVID era. A user survey carried out in New Delhi showed that there is a significant shift of choice from public modes to private modes [15]. The same study indicated that the shift is likely to be a long-term trend. Results in the study also indicated towards a shift of business processes to an online mode as well as increased anxiety caused by the COVID-19 and its various implications on the travel patterns of the respondents. There is also published research for mathematical modelling of the impact of COVID-19 on travel patterns in India [16]. The results of the study indicate a significant inertia to maintain the pre-COVID travel pattern as well as a high propensity to of changed business processes (e.g. work from home, online shopping, etc.) and shift towards private modes.

\subsection{Impact of COVID-19 on shared mobility}

Shared mobility has been established as having the maximum disruptive potential over urban transportation system [17]. It is also established that short term access to shared vehicles instead of using owned vehicles offer a possibility of vast change in the urban transportation market [18]. This phenomenon is due to changing demographics and cultural shifts, new social attitudes and advancement of internet and mobile phone technology. The global market for shared modes of transportation is expected to grow from US\$ 1.1 billion in 2015 to US\$ 6.5 billion by 2024 [19]. However, these predictions are from the pre-COVID era and trends are expected to change significantly.

Studies on shared mobility in the post COVID scenario are limited. An expert's opinion study believes that COVID-19 affects the overall sustainability of the shared mobility market. The demographics using the shared mobility market is vulnerable to perceiving the shared modes as unsafe due to a lack of trust on co-passengers, drivers and the service. The study also reveals that the public trust should be bolstered by implementing social distancing and COVID protection norms [20]. Data on usage of public bike riding system from Thessaloniki, Greece revealed higher attraction of shared bikes during the pandemic [21].

\subsection{Impact of COVID-19 guidelines in Bangalore}

The COVID-19 was an unprecedented event in recent history. In cue with several other COVID-19 impacted countries, the Government of India imposed strict curfew measures to restrict the spread of the disease. The curfew regulations or 'lockdown for containment of COVID-19 epidemic' as it was termed by the Government of India was announced on March 25th 2020 for a period of 21 days which was further increased in phases till May 3rd 2020 and finally till May 31st 2020. The guidelines instructed closure of offices of Government of India, offices of the States, commercial and private establishments, industrial establishments, transport services, hotels and hospitality, educational institutions and all social and gatherings [22]. These guidelines were slightly relaxed starting from June 1st 2020 with private offices; commercial establishments were allowed to operate with operating protocols of social distancing and reduced working hours. The normalcy was restored in a phased manner over a period of 8 months till February 2021. COVID-19 vaccination was launched country wide on 26th January 2021 staring with front line workers and progressing for other age groups. 
Data analysed from Google mobility reports reflected a $40 \%$ reduction in traffic to work places and 36\% reduction to retail and entertainment in Bangalore [23]. Bangalore being the 'Silicon Valley of the East' is home to the largest cluster of IT and ITES companies in India. Market data indicators from the pre-COVID scenario reflected shared mobility to be a popular mode of transport in the city The Bangalore shared mobility market is represented by service providers from ride sourcing (use of online platforms to connect passengers with drivers and automate reservations, payments, and customer feedback), ride-sharing (adding passengers to a private trip in which driver and passengers share a destination), ride splitting (a type of ride sourcing that allows customers requesting a ride for one or two passengers to be paired in real time with others traveling along a similar route), and bike sharing (shortterm bike rental) [24] categories. There are about 12 major service providers in the shared mobility market. A user survey showed Ola, Uber and Bounce to occupy major share. Cars, motorbikes and auto-rickshaws comprise the major vehicular modes in the shared mobility market. It is also noted that these services were used by users across social, economic and age groups for trips of essential and non-essential nature all across the city [25].

There is no data on user perception on shared mobility in the context of COVID-19 for Bangalore. This paper intends to bridge the gap by presenting survey results focusing around impact of COVID-19 outbreak user perception towards shared mobility and changed travel patterns in Bangalore city.

\section{METHODOLOGY}

\subsection{Study area}

Bangalore is one of the prominent metropolises in India and well as Asia. Its population of 8.6 million is representative of the major cities in Asia like Bangkok (8.2 million), Seoul (9.9 million), Lahore (10 million) and Mumbai (12.4 million). The city is India's Silicon Valley, and attracts people from all across the country. Bangalore has the largest cluster of IT based service industry in the country. The city has a strong digital infrastructure and is an incubation centre for start-ups. Many of the digital business processes that were adopted in other economic sectors in response to the pandemic were already present and running is a large section of the Bangalore's economy. It was also seen that preparedness and support for remote and digitally enhanced working were one of the highest in the IT\&ITES sector. Hence the adaption and the long term extension of such process are expected to continue for a foreseeable future [16].

There changes are expected to have an impact of the travel pattern and the choice of travel mode in the city in the long term mobility planning. Hence Bangalore appears to be an excellent are for exploratory research on the impact of COVID-19 on shared mobility modes.

\subsection{Survey design and implementation}

The purpose of this research is to document impact of COVID-19 on shared mobility services in Bangalore. Similar research globally has established the use of user survey in studies related to mobility choice as well as specifically the case of shared mobility in the background of COVID-19 [18]. An online survey was designed with 26 questions, to understand the trip characteristics and preferences of mobility in the post COVID outbreak period. The questionnaire had four sections with relevant questions on demography, pre COVID travel behaviours, post COVID travel behaviour and perception towards shared mobility modes in the post COVID scenario. A combination of close-ended questions (multiple selection, linear 
scale) and open-ended questions were included. The survey instrumented was pre-tested with 10 pilot surveys and modified slightly based on user feedback. The survey was conducted in the month of February 2021.

Convenience sampling method was used for the survey implementation which is an established method in exploratory surveys. A database of users, proprietary to our company was used to disseminate the survey. Google forms, a freely available software was chosen as the platform to reach the respondents. The forms were emailed to 1,000 potential respondents whom we assumed to be residents of Bangalore or frequent and occasional visitors to the city.

\subsection{Analysis}

Out of 1,000 forms sent out, 120 completed surveys were received, which is about $11 \%$ response rate. Out of 120, 101 responses were used for analysis. The rest (19) were discarded due to data inconsistency. Considering ethics of research, we did not collect any personal information such as name or other identifiers. The responses were found to be reasonably well distributed spatially, across age groups, working groups, income groups and gender groups. The responses were exclusively from residents and visitors of the city which further strengthened the results. The responses were hence considered as representative of the user base in the city for the purpose of exploratory research. Data was collated in a statistical database analysis software for gathering statistics for various indicators. Correlation analysis was carried out using SPSS software, to understand the association between the variables through computation of Pearson's Correlation coefficients. Given the exploratory nature of the survey, the correlation analysis provided preliminary understanding on the strength of association between the variables used in the survey.

\section{RESULTS OF SURVEY}

\subsection{Respondent profile}

Distribution of the samples by the postal codes collected during the survey show that samples are reasonably well distributed within the city. About $97 \%$ of the respondents were residents of Bangalore city, about $70 \%$ were male respondents and $30 \%$ were female. Majority of the respondents $(77 \%)$ belonged to the age group 25-77 years where as other were from a higher or a lower age group. The respondents were almost equally distributed among the middleincome group (\$214-\$714 per month), the upper middle-income group $(\$ 714-\$ 1,428$ per month) and the higher income group (more than $\$ 1,428$ per month). About $73 \%$ of the respondents owned multiple vehicle while only $1 \%$ reported owning no vehicle (see Fig. 1 and Table 1).

\subsection{Impacts on trip characteristics due to COVID-19}

During the survey, the lockdown measures were significantly relaxed and India as a whole was witnessing a downward curve of COVID-19 infections. Vaccination drive was also in implementation. The study reveals that there were significant changes in trip characteristics after COVID-19. 30\% of the respondents reported no daily travel after COVID-19 outbreak in comparison to $10 \%$ before the pandemic. Significant reductions (13\% and $25 \%)$ were also noticed in users commuting more than $10 \mathrm{~km}$ and $15 \mathrm{~km}$ per day before the pandemic as seen in Fig. 2. 


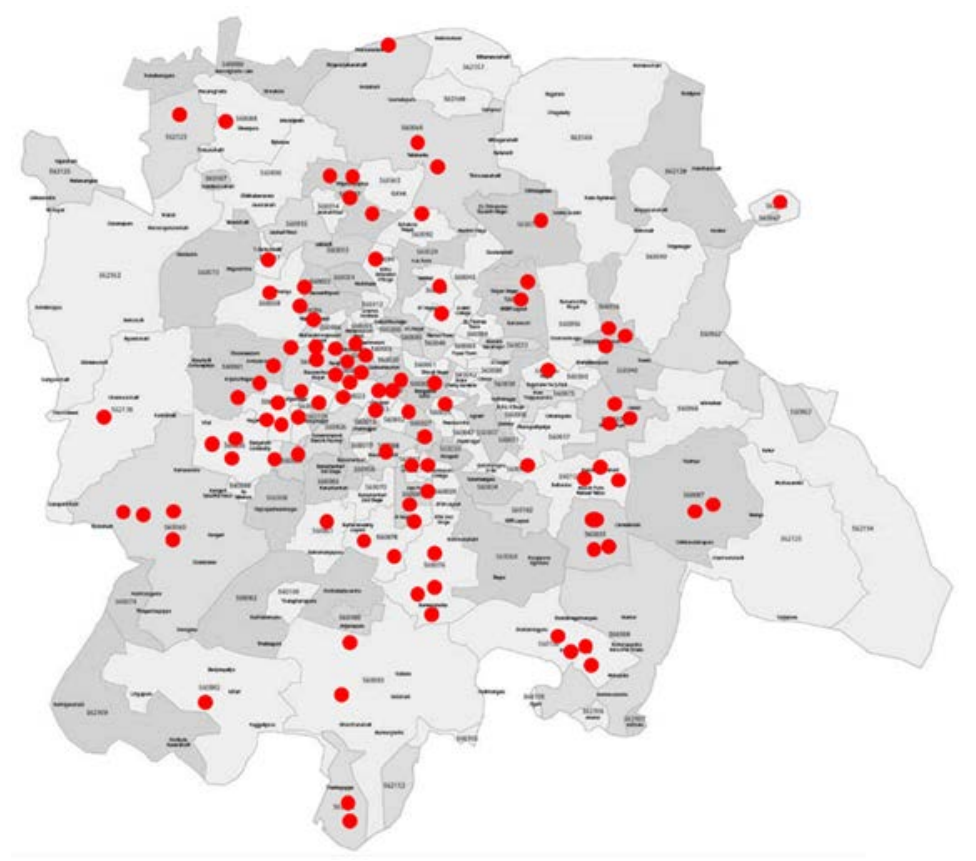

Figure 1: Distribution of survey samples in Bangalore city.

Change in Trip Length after COVID-19

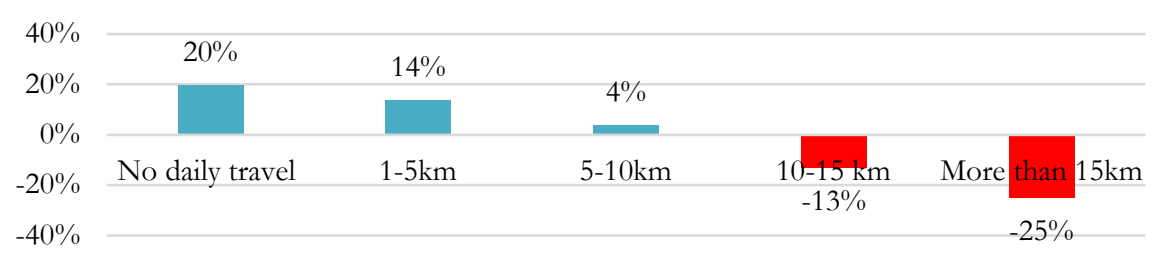

Figure 2: Change in trip length after COVID-19.

$19 \%$ of the respondents reported similar pattern of shared mode usage after the COVID19 while $81 \%$ reported either a reduction or non-existence of such trips. There was also a transformation of mode choice after the COVID-19 among the respondents who reported a shift from shared mode. About $24 \%$ reported transfer to self-owned cars, $18 \%$ of self-owned scooter while $54 \%$ reported shifting to a combination of bicycle, cars and scooters.

About $70 \%$ of the respondents described cost per trip to be less than INR 300 (US $\$ 4.28$ ) before the COVID-19 outbreak while 25\% spent between INR 300-INR 500 (US\$4.28\$7.14). There was an increase in travel cost reported by $19 \%$ of the respondents while $33 \%$ reported not being able to gauge the difference in daily travel cost as they had shifted to personal modes. $49 \%$ reported decrease in travel costs after the COVID-19. Among the respondents reporting decreased travel cost, $32 \%$ stated shift of schooling or working to a work-from-home mode while the other reported reduction in non-essential travel. 
Table 1: Respondent demographics.

\begin{tabular}{|c|c|c|}
\hline \multirow{2}{*}{ Indicators } & \multicolumn{2}{|c|}{ Survey } \\
\hline & Survey response & Percentage \\
\hline \multicolumn{3}{|l|}{ Gender } \\
\hline Male & 71 & 70 \\
\hline Female & 30 & 30 \\
\hline $\mathrm{N}$ & 101 & \\
\hline \multicolumn{3}{|l|}{ Resident status } \\
\hline Resident & 98 & 97 \\
\hline Frequent visitor & 1 & 1 \\
\hline Occasional visitor & 2 & 2 \\
\hline $\mathrm{N}$ & 101 & \\
\hline \multicolumn{3}{|l|}{ Age (years) } \\
\hline Less than 18 years & 1 & 1 \\
\hline $18-25$ years & 9 & 9 \\
\hline $25-50$ years & 78 & 77 \\
\hline More than 50 years & 13 & 13 \\
\hline $\mathrm{N}$ & 101 & \\
\hline \multicolumn{3}{|l|}{ Employment status } \\
\hline Employed & 69 & 67 \\
\hline Unemployed & 28 & 33 \\
\hline Part-time employment & 4 & \\
\hline $\mathrm{N}$ & 101 & \\
\hline \multicolumn{3}{|l|}{ Type of employment } \\
\hline Government worker & 6 & 7 \\
\hline Private company & 60 & 65 \\
\hline Frontline worker (medical/police) & 2 & 2 \\
\hline Business & 24 & 26 \\
\hline $\mathrm{N}$ & 92 & \\
\hline \multicolumn{3}{|l|}{ Income (INR, lakhs per annum) } \\
\hline Less than $15,000(\$ 214)$ & 6 & 6 \\
\hline $15,000-50,000(\$ 214-\$ 714)$ & 27 & 27 \\
\hline $50,000-100,000(\$ 714-\$ 1,428)$ & 25 & 25 \\
\hline More than $1,00,000(\$ 1,428)$ & 33 & 33 \\
\hline No response & 10 & 10 \\
\hline $\mathrm{N}$ & 101 & \\
\hline \multicolumn{3}{|l|}{ No of vehicle owned } \\
\hline Single vehicle & 26 & 26 \\
\hline Multiple vehicles & 74 & 73 \\
\hline No vehicle & 1 & 1 \\
\hline $\mathrm{N}$ & 101 & \\
\hline \multicolumn{3}{|l|}{ Vehicles owned } \\
\hline Car & 72 & 44 \\
\hline Bicycle & 24 & 15 \\
\hline Motorcycle/scooter & 67 & 41 \\
\hline $\mathrm{N}$ & 163 & \\
\hline
\end{tabular}




\subsection{Perceptions related to COVID-19}

User perception related to the shared services and COVID-19 collected though a 5-point Likert scale revealed that about $47 \%$ of the respondents perceived moderately high or high risk of COVID-19 infections from usage of shared modes. About $92 \%$ of this group used personal vehicles after the COVID-19 outbreak.

COVID-19 risk perception from shared mobility

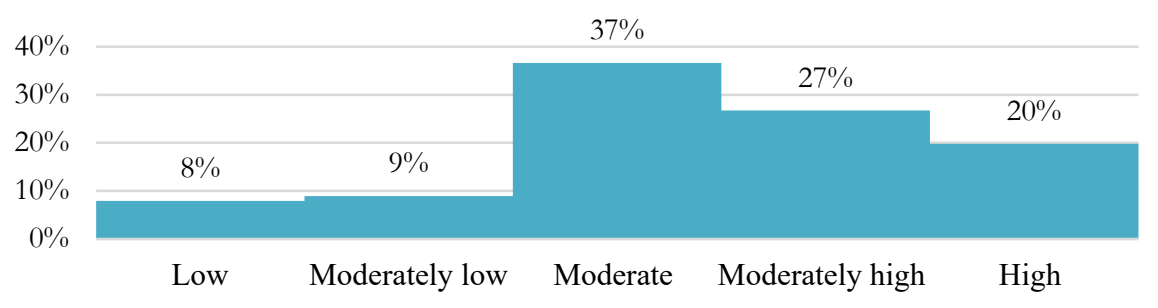

Figure 3: COVID-19 risk perception from shared mobility.

However, $62 \%$ of respondents reporting similar pattern of shared mode usage pre and post COVID outbreak stated shared mobility to either as a safer mode compared to other or not being perceived as a huge risk. About $30 \%$ of respondents stated less than average implementation of COVID-19 safety measure in the vehicles. $81 \%$ of this group reported using shared services at least once after the COVID outbreak. Measures such as reduced no of users per trip, vehicle sensitisation, drivers' body temperature reporting was acknowledged by the responding people. About $40 \%$ of the surveyed users reported likeliness of using shared modes in the future where as $31 \%$ was unlikely and $30 \%$ were neutral about the situation.

\subsection{Correlation analysis}

Correlation analysis was carried out to using Pearson's correlation coefficient method to analyse the association between the variables. The data was suitably treated and the correlation matric was formed using SPSS software.

Results showed few meaningful correlations between the variables. A large number of correlations were found negligible $(-0.20>\mathrm{R}>0.20)$, some of the correlations were weak $(-0.20>\mathrm{R}>-0.35)$ or $(0.20<\mathrm{R}<0.35)$. Few correlations were found to be 'fair or moderate' correlations $(-0.35>\mathrm{R}>-0.50)$ or $(0.35<\mathrm{R}<0.50)$ and few were found to be 'strongly considerable' high correlation $(-0.5<\mathrm{R}<0.70)$ or $(0.5>\mathrm{R}>0.7)$. Analysis of $\mathrm{p}$ value revealed some of the variables to be significantly correlated. A section of the correlation matric has been presented in Table 2 .

Positive correlation was observed between income level and car ownership. Income level as well as scooter ownership were positively correlated with mode switch to scooter post COVID. It was also observed that perception of high risk from shared mobility was negatively correlated with maintaining of pre-COVID travel modes. It was also found that perception of shared modes taking adequate COVID safety measures was significantly correlated to likeliness of usage of shared modes in future. 


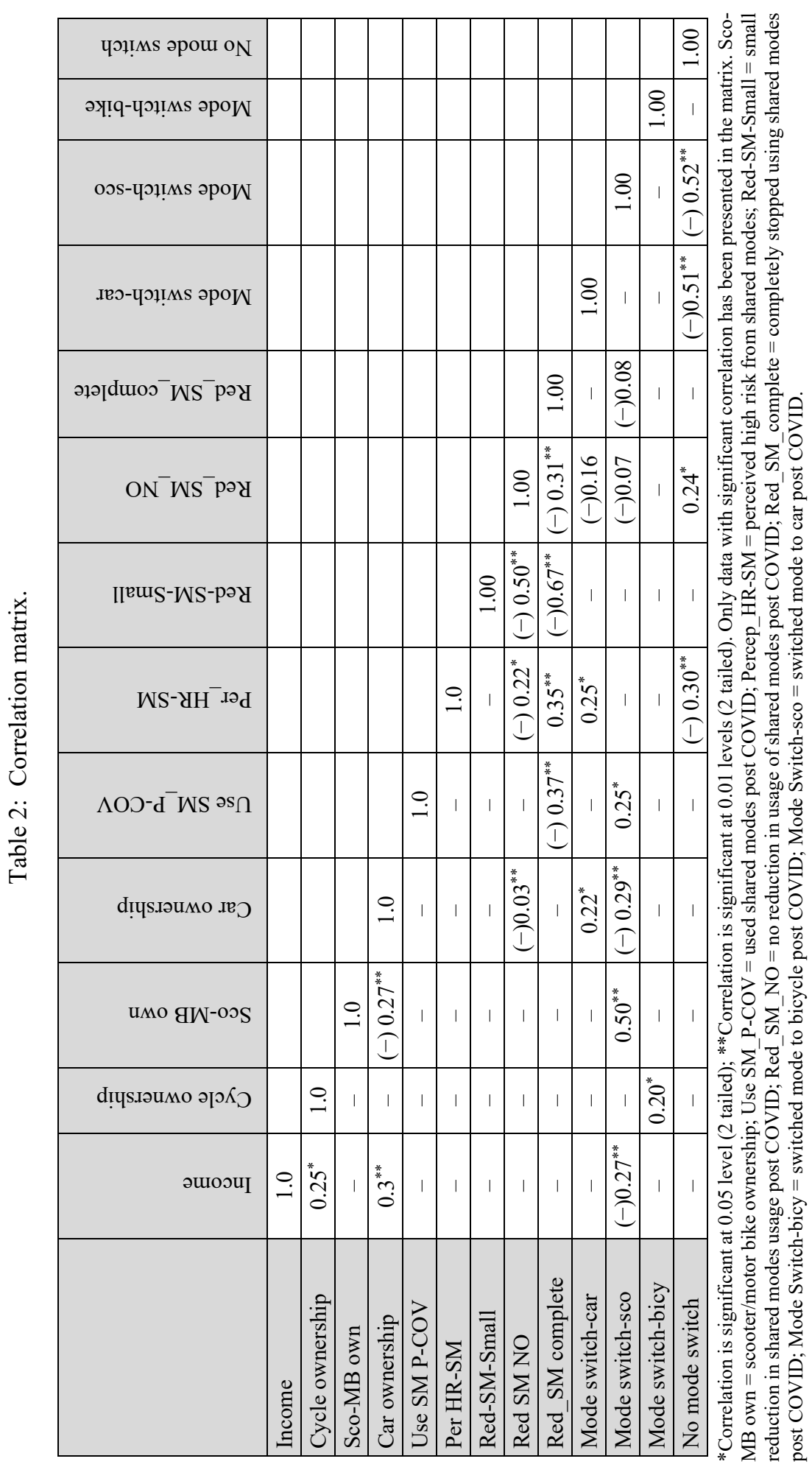




\section{INFERENCE}

The study provides useful insights into the impact of the COVID-19 on the usage of shared mobility modes in Bangalore city. The survey results indicate that COVID-19 has significant impact on the travel patterns among the commuters. A large segment of the commuters from the private industry resorted to work-from-home mode. Travelling distances had reduced from before COVID. Significant part of the users of shared modes in the pre-COVID era shifted to personal vehicles like cars and scooters. There was reduced spending on travel for a large segment of the users either due to work-from-home or due to reduction in nonmandatory travel.

Among the group which continued usage of shared mobility modes after the COVID-19 outbreak, perception of linkage between usage of shared modes and COVID were low. In some cases, shared modes were considered safer than other modes. However, the segment of people retaining similar usage of share modes in pre and post COVID era was very low.

The travel choices were altered. Majority of respondents perceived a linkage between usage of shared modes and COVID-19 infections. Perceptions of safety were also altered. Personal vehicles like cars, scooters and bicycle as well as walking were perceived as safe. About a third of the surveyed population expressed less than average satisfaction level with the implementation of the COVID-19 safety measures in the shared modes. There were some significant correlations observed between the surveyed variables. Income level was revealed to be significantly correlated to car ownership and switching of travel mode to scooter post COVID. Ownership of car and scooter were significantly correlated to switching of travel mode to car and scooter respectively in the post COVID scenario. There was significant correlations found between perception of COVID risk from shared modes with change in travel mode post COVID as well as perception of COVID safety measures with likeliness of usage of shared modes in future.

\section{CONCLUSION}

This paper presented the trip characteristics and user perception about shared mobility after the outbreak of the COVID-19 during a period when the restrictions related to COVID-19 were significantly relaxed and vaccination was under implementation. There were no restrictions in people's movement during this period except personal COVID protection advisories like wearing of mask, sanitisation, social distancing and reducing non-mandatory travel. During the period of the survey the COVID-19 infection curve was in a downward trajectory and majority of the business and activities has resume to business as usual except mandatory closure of schools below the age of 12 . Even though the situation cannot be attributed as a 'normal scenario' however in the post COVID-19 era, it would appear as the 'new normal'. Unlike the west, India had not seen the second or the third wave of COVID19 infection surge during the period of the survey. However, going by the global trend, a second wave is a very realistic possibility. Coupled with that, the altered business processes and nature of economic activities like work-from-home and online schooling could possibly have a longer life cycle than the life cycle of the pandemic. Hence the results of the survey during this period can be considered representative of people's perception towards shared mobility modes and travel patterns for the foreseeable future.

Research and data related to shared mobility is in a nascent stage in India. This paper presents exploratory research data and is one of the first documented studies on impact of COVID-19 on shared mobility in Bangalore. Bangalore is one of the prominent metropolises of India and user perceptions about shared mobility could be representative of the trend in major cities in the country. The research also presented correlations between some factors of 
the survey. In the context of the high growth projected for this market in the past, this study would be a significant first step of greater research on sustainability of the shared mobility market.

\section{ACKNOWLEDGEMENTS}

I would like to express my gratitude to Sky Group for supporting and funding the research. I also convey a huge vote of thanks to my peers in research and practice for advice and inputs and to my family for their unconditional support.

\section{REFERENCES}

[1] Strategic Assessment of Shared Mobility Market in India, Frost and Sullivan, Sep. 2019.

[2] NITI Aayog, Moving Forward Together: Enabling Shared Mobility in India, Rocky Mountain Institute, and Observer Research Foundation, 2018.

[3] Government of India Portal on COVID-19. https://www.mygov.in/covid-19.

[4] Bruhat Bangalore Mahanagara Palike (Bangalore Municipal Corporation) portal on COVID-19. https://covid19.bbmpgov.in/.

[5] Corona Virus Resource Centre, John Hopkins University \& Medicine. https://coronavirus.jhu.edu/map.html.

[6] Shaheen, S., Bell, C., Cohen, A. \& Yelchuru, B., Travel Behaviour: Shared Mobility and Transportation Equity, Federal Highway Administration, 2017.

[7] Shaheen, S., Cohen, A. \& Martin, E.U.S., Department of transportation's mobility on demand initiative: moving the economy with innovation and understanding., Transportation Research Circular, Washington, DC, USA, 2018.

[8] Dias, F.F., Lavieri, P.S., Garikapati, V.M., Astroza, S., Pendyala, R.M. \& Bhat, C.R., A behavioral choice model of the use of car-sharing and ride-sourcing services. Transportation, 44, pp. 1307-1323, 2017.

[9] Yogesh, K. et al., Impact of COVID-19 pandemic on information management research and practice: Transforming education, work and life. International Journal of Information Management, 55, p. 102211, 2020. ISSN 0268-4012.

[10] Carrington, D., UK road travel falls to 1955 levels as Covid-19 lockdown takes hold. The Guardian, 3 Apr. 2020.

[11] De Vos, J., The effect of COVID-19 and subsequent social distancing on travel behavior. Transportation Research Interdisciplinary Perspectives, 5, 2020.

[12] Beck, M.J. \& Hensher, D.A., Insights into the impact of COVID-19 on household travel and activities in Australia - The early days under restrictions. Transport Policy, 96, pp. 76-93, 2020.

[13] Mohammadian, A., Shamshiripour, A., Rahimi, E. \& Shabanpour, R., TRB webinar: How much will COVID 19 affect travel behavior, 2020.

[14] Bucsky, P., Modal share changes due to COVID-19: The case of Budapest. Transportation Research Interdisciplinary Perspectives, 8, p. 100141, 2020.

[15] Singh, V., Gupta, K., Agarwal, A. \& Chakrabarty, N., Psychological impacts on the travel behavior post-COVID-19. WP \#33, Indian Institute of Technology Roorkee, Jul. 2020.

[16] Bhaduri, E. et al., Modelling the effects of COVID-19 on travel mode choice behaviour in India. Transportation Research Interdisciplinary Perspectives, 8, 2020.

[17] Cohen, B. \& Kietzmann, J., Ride on! Mobility business models for the sharing economy. Organization \& Environment, 27, pp. 279-296, 2014. 
[18] Shaheen, S., Chan, N., Bansal, A. \& Cohen, A., Shared Mobility: A Sustainability and Technologies Workshop-Definitions, Industry Developments, and Early Understanding, Transportation Sustainability Research Center, University of California, Berkeley and California Department of Transportation: Richmond, CA, USA, 2015.

[19] Coates, M., The evolution of car sharing. Clean Fleet Report, 2016.

[20] Shokouhyar, S. et al., Shared mobility in post-COVID era: New challenges and opportunities. Sustainable Cities and Society, 67, 2021.

[21] Nikiforiadis, A., Ayfantopoulou, G. \& Stamelou, G., Assessing the impact of COVID19 on bike-sharing usage: The case of Thessaloniki, Greece. Sustainability, MDPI, 2020.

[22] Ministry of Home Affairs, Government of India, Guidelines on the measures to be taken by Ministries/Departments of Government of India, State/Union Territory Governments and state and union territory authorities for the containment of COVID19 Epidemic in the country, Mar. 2020.

[23] Google, COVID-19 community mobility reports. Accessed on: Feb. 2021.

[24] Shared mobility and the transformation of public transit. TCRP Research Report 188, Transportation Research Board, 2017.

[25] Ghosh, G., Characteristics of shared mobility in Bangalore. WIT Transactions on the Built Environment, vol. 200, WIT Press: Southampton and Boston, 2020. 